\title{
GUSTAV MAHLER: EL HOMBRE Y SU MÚSICA
}

Venustiano Reyes*

\section{Nota Preliminar}

$\mathrm{E}_{\text {ste mes de mayo recordamos la }}$ muerte de uno de los compositores más importantes del siglo $\mathrm{XX}, \mathrm{y}$ tal vez uno de lo más grandes de todos los tiempos: Gustav Mahler, nacido el 7 de julio de 1860 y muerto el 18 de mayo de 1911 .

En su catálogo figuran nueve sinfonías completas, una décima inconclusa y varios ciclos de lieder (canciones), entre los que destacan cinco Kindertotenlieder (Canciones para los niños muertos), compuestos en 1902; doce Lieder aus 'Des Knaben Wunderhorn' (Canciones del corno mágico del muchacho), de 1899; cuatro Lieder eines fahrenden Gesellen (Canciones de un compañero errante), de 1884; y Das lied von der Erde (Canción de la Tierra), que en realidad debe considerarse como una sinfonía, ya que Mahler, supersticioso por el hecho de que Beethoven, Schubert y Bruckner murieron poco después de componer sus respectivas novenas sinfonías, prefirió denominar la composición que iniciaba después de su octava sinfonía como lieder. De las diez sinfonías, cinco están acompañadas por voz humana y cinco son instrumentales. Cada una de estas sinfonías es grande, en todos los sentidos de la palabra, y son un universo en sí mismas. Desgraciadamente, no puedo abordar con detalle en este ensayo cada una de estas formidables creaciones, si tomamos en cuenta que, además de intentar

* Escritor. 
dar un panorama general al lector de la obra del genial compositor, trataré - muy brevemente- la interesante relación que sostuvo con Alma Schindler y el psicoanálisis que le practicó Freud; por si fuera poco, también incluyo una breve guía de las mejores grabaciones de Mahler en disco compacto. Así que sólo he de referirme a las obras que considero las más importantes, aunque no faltarán, con justa razón, los que me reprochen el haber omitido comentarios a composiciones como las sinfonías primera, cuarta, séptima y décima, y a importantes ciclos de lieder. A todos ellos, ofrezco disculpas.

\section{Introducción}

Parece paradójico que la obra de un judío errante que se sentía apátrida y sin identidad definida, sea extraordinariamente original. Es precisamente el caso con Mahler. Los austríacos lo consideraban bohemio, a pesar de haber nacido en la Moravia austríaca; los bohemios, austríaco; los alemanes se referían a él como 'el austríaco' o 'el judío'; los judíos lo veían como 'el cristiano’, pues se convirtió a la fe católica. Y, sin embargo, la obra de Mahler no podría tener mayor identidad, no podría ser más original, no podría estar más definida. En fin, un genio absoluto y verdadero, como pocos han existido en la humanidad, y que, entre otras cosas, tuvo la virtud de exponer, como nadie, los secretos más íntimos del ser; y no sólo del ser humano, sino del ser universal (esse comune) y del Creador mismo (ipsum esse subsistens). En suma, para muchos Gustav Mahler es un verdadero profeta del espíritu humano y del anima mundi. El incomparable Thomas Mann (Premio Nobel de literatura, 1929) se refirió a él en estos términos: "el hombre que, como creo, expresa el arte de nuestro tiempo en su forma más profunda y sagrada".

De cualquier forma, lo paradójico en Mahler no se limita a esto. Cabe preguntar cómo es posible que, habiendo sido uno de los mejores directores de ópera de todos los tiempos - entre sus puestos figuran el de director de la Ópera Estatal de Viena y director de la Ópera Metro- 
politana de Nueva York-, no haya compuesto ninguna -aunque en su juventud hizo algunos intentos que abandonó, como su ópera Herzog Ernst von Schwaden, cuyo manuscrito se perdió-. Y, no obstante, todo el drama de la ópera se encuentra en sus sinfonías, tanto en las que son únicamente instrumentales como en las que también incluyen voz humana. El drama emocional difícilmente puede encontrar rival en toda la historia de la música: el pathos es tan agudo e intenso como en Beethoven, las proporciones son tan vastas como en Bruckner, el cromatismo y la orquestación son tan exuberantes como en Wagner, ¡la fuerza es tan demoledora como en Beethoven, Bruckner y Wagner juntos! La música de Mahler lo contiene todo, lo abarca todo, lo abraza todo (embraces everything, l'abbraccia tutto, l'embrasse tout): sonidos de la naturaleza, incluida la voz de Dios, danzas campiranas, sensualidad y espiritualidad, lo grotesco y lo sublime, ironía, sarcasmo, crudeza directa y sin rodeos. Mahler expresa el todo y para ello lo exige todo. Con él, la orquesta adquiere dimensiones antes desconocidas. Hay quienes opinan que nuestro compositor no es otra cosa que un interesante caso psicológico de megalomanía. Tampoco faltan aquellos quienes, más por reflejar otras opiniones -infundadas, por cierto-que por hablar con conocimiento de causa, lo consideran un ser acomplejado que, para superar ese problema de inferioridad, requería grandes fuerzas. Todo esto es falso. La música de Mahler no puede considerarse, ni con la peor de las voluntades, como la alucinación de un hombre con delirios de grandeza, sino como la visión de un hombre grande que ve más allá de lo que puede ver el hombre común, la poderosísima creación de un genio privilegiado que tenía la capacidad de abarcarlo todo, y más. Ese es Mahler, el gigante, el titán.

Como director debutó casualmente cuando suplió al afamado Arthur Nikisch en enero de 1887. Para dicha temporada, la atracción principal era la puesta en escena del ciclo completo de "El Anillo del Nibelungo" de Wagner. Mahler se había resignado a quedar aparte cuando la suerte, o el destino, determinó que Nikisch cayera enfermo. Fue así que el joven judío apareció ante el público de Leipzig dirigiendo Die Walküre (La Valquiria) y Siegfried. Su actuación fue 
extraordinaria, a grado tal, que el Neues Stadtheater de Leipzig lo contrató para que en la temporada de mayo dirigiera el ciclo completo. La producción fue en verdad sobresaliente, y ante el exigente público y la dura crítica quedó como un genio de la interpretación. Su fama como director creció y traspasó límites que Mahler no había imaginado. Tiempo después, en los primeros años de la última década del siglo XIX, Brahms y Hanslik, sobrecogidos por una producción de Don Giovanni en Budapest, lo recomendaron ampliamente para que ocupara el puesto de director de la Ópera de Viena, en ese entonces la máxima casa operística del mundo. Mahler no necesitaba recomendaciones -sus credenciales eran por demás admirables-. Luego de varias temporadas como director invitado, fue designado director titular en septiembre de 1897. Al año siguiente, después de la renuncia de Richter, Mahler fue invitado como director de los Conciertos Filarmónicos -lo que hoy en día es la Orquesta Filarmónica de Viena-. Inmediatamente se sintió un incremento en el público. La gente quería escuchar al controvertido genio, al joven director autoritario que rompía las reglas y cuyas interpretaciones no eran respetuosas de la convención ni de la tradición. Mahler simplemente cambió las reglas: nunca músico alguno

124 en la orquesta fue presionado ni insultado tanto por el director. Era un auténtico tirano al podio, un dictador cuyos impulsos explotaban con el mínimo error. Nadie antes pudo haber soñado que un director concentrara tan inmenso poder sobre sus músicos. Ellos se quejaban, pero ante la perfección del Maestro cedían, pues las interpretaciones de Wagner o Beethoven bajo su batuta no tenían rival en el mundo entero. También fue duro con el público. Antes la gente llegaba a la hora que quería, y hacía toda clase de ruidos; incluso se saludaban, como si la representación fuese una reunión burguesa. Mahler acabó con esto y prohibió la entrada una vez comenzado el concierto. Quien llegara tarde tendría que esperar a que finalizara la primera obra del programa. 


\section{Segunda Sinfonía: La Resurrección}

Su fama como director opacó sus logros artísticos, hasta que el estreno en Viena de su segunda sinfonía, "La Resurrección”, lo estableció como uno de los compositores más importantes de le época. Arnold Schoenberg asistió al estreno y dijo: "Fui atrapado, en ciertos pasajes, por una excitación que se manifestaba aún físicamente. ¡Estaba sobrecogido, completa y absolutamente sobrecogido!"

Se ha dicho que esta sinfonía marcó musicalmente la conversión de Mahler al catolicismo (1897) y que es símbolo de su nueva fe, lo cual no es del todo correcto. Las preocupaciones de Mahler sobre las cuestiones más profundas de la vida, la muerte, Dios y la naturaleza, son de corte más bien agnóstico. Hay quienes han afirmado, no sin razón, que la religión como manifestación del establishment le tenía sin cuidado, y que su conversión se debió más a cuestiones políticas que a creencias arraigadas, ya que era impensable en la época de su designación en Viena, que un judío pudiera sostener tan alto cargo. Mahler nunca aclaró los verdaderos motivos de su conversión, ni tenía por qué hacerlo. De cualquier manera, desde antes de adherirse a la fe católica, y en gran medida debido a los ataques antisemitas de que fue objeto, Mahler ya se había alejado del judaísmo. En esos años varios judíos abandonaron su religión. Resultaba inimaginable que un profesor de la universidad o un alto funcionario del Estado fuera judío; era menester ser bautizado y cabe pensar que Mahler premeditó su conversión para evitarse cualquier obstáculo que lo marginara de su futuro puesto en Viena. Se deba o no la segunda sinfonía a cuestiones de fe, lo cierto es que dicha obra es un hito en la historia de la música, como puede interpretarse de lo dicho por el famosísimo director Hans von Bülow, ${ }^{1}$ quien había escuchado a principios de los años 90 una versión de la "Resurrección" en piano. Según el propio compositor, von Bülow dijo: "si esto es música, entonces yo no entiendo nada

${ }^{1}$ Antes esposo de Cósima, hija de Franz Liszt. 
sobre música”. Esta sentencia es ambigua. Bien puede pensarse que a Bülow le disgustó la obra o que cayó sobrecogido como después caería Schoenberg. Me inclino a pensar que se trata de lo segundo y que la frase del director alemán, así entendida, es sumamente elocuente y expresiva. En efecto, con Mahler termina la música como había sido concebida desde que el sistema tonal de composición fue ganando terreno al modal. Desde principios del siglo XVII hasta finales del XIX los compositores escribían sus obras en tonos determinados. Wagner -tal vez Beethoven con sus audaces y geniales últimos cuartetos de cuerdas- empezó a destruir el sistema tonal con su ópera "Tristán e Isolda" (the "Tristan chord") y, aunque llevó al tono a los límites de su existencia, fue Mahler el que acabó con el trabajo. Sobre los cimientos construidos por él y por Wagner descansa gran parte de la música artística del siglo XX, así que podríamos trazar una línea regresiva que inicie en el serialismo de Schoenberg, Berg y Webern, y que fluya hacia el post-romanticismo de Richard Strauss y Mahler, el romanticismo exaltado de Wagner, el romanticismo moderado de Brahms, el heroísmo indómito de Beethoven, el clasicismo de Haydn y Mozart, hasta desembocar en el barroco de Haendel y Bach; es decir,

126 una riquísima tradición musical cien por ciento alemana, probablemente la tradición musical más importante de todos los tiempos.

La segunda sinfonía contiene versos del poeta Klopstock, a los que Mahler añadió los suyos. He aquí un fragmento de estos versos. Inusitada es su belleza e insondable su profundidad. Desmienten la arraigada idea de Mahler como un hombre atormentado y autodestructivo.

¡Resucitarás, sí resucitarás, / polvo mío, tras breve descanso! / Vida inmortal te dará quien te llamó. / ¡Para volver a florecer has sido sembrado! / El dueño de la cosecha va / y recoge las gavillas, / y al final a nosotros que morimos. / ¡Oh, créelo, mi corazón nada se pierde de ti! / Tuyo es, sí, tuyo, lo que anhelabas, / ¡lo que ha perecido resucitará! / ¡Oh, créelo: no has nacido en vano, / no has sufrido en vano! / ¡Lo nacido debe perecer, / lo que ha perecido debe resucitar! / ¡Cesa de temblar! / ¡Disponte a vivir! / ¡Oh dolor, tú que todo lo colmas, / he escapado de 
ti! / ¡Oh, muerte, tú que todo lo doblegas, / ahora has sido doblegada! / Con alas que he conquistado / en ardiente afán de amor, / levantaré el vuelo / hacia la luz que no ha alcanzado ojo alguno. / ¡Con alas que he conquistado, / levantaré el vuelo! / ¡Moriré para vivir! / ¡Resucitarás, sí, resucitarás, / corazón mío, en un instante! / Lo que has latido / habrá de llevarte a Dios.

\section{Tercera Sinfonía}

Con la tercera sinfonía, sobre textos de Nietzsche, Mahler creó un verdadero coloso que superó en magnitud, aunque no en belleza, a sus anteriores creaciones. El monumento musical tiene una duración de una hora y media que fluye a través de seis movimientos, con los que Mahler se separó del tradicional esquema sinfónico. Con esta obra da cuenta de lo que para él es la naturaleza, pero mucho más allá que meras descripciones de tempestades, arroyos, aves y bosques. Amante de la naturaleza como Beethoven - no sin razón se ha dicho que la tercera sinfonía de Mahler es su pastoral, comentario que lejos de entusiasmar al compositor lo irritaba-, centraba su atención en lo que él denominó las fuerzas elementales o la naturaleza como expresión de Dios. Bruno Walter se refería a la tercera como "la plenitud dionisíaca de la naturaleza". Es curioso que Mahler, para entender la naturaleza como expresión de Dios, se haya valido de los textos del filósofo que proclamó dionisíacamente 'la muerte de Dios'. En el cuarto movimiento hay un pasaje singular y bellísimo tomado de Así habló Zaratustra:

¡Ah, hombre, está atento! / ¿Qué dice la profunda medianoche? / Yo dormía y dormía, / de un profundo sueño he despertado: / El mundo es profundo, / y más profundo de lo que el día ha pensado; / profundo es su dolor. / El placer es más profundo que el sufrimiento: / el dolor dice: ¡Pasa! / mas todo placer quiere eternidad, / quiere profunda eternidad. 
Nietzsche escribió en una carta, poco después de componer su Zaratustra (1883-1885): “¿En realidad a qué género pertenece mi Zaratustra? Casi creo que al de la sinfonía." Este comentario revela la sensibilidad musical de Nietzsche -quien, por cierto, tuvo intentos serios de composición-y la percepción poética de Mahler, que decía: "la música no es más que un sonido de la naturaleza”. En ese sentido, es válido sostener que la interpretación que debe darse a esta sinfonía es la de un grandioso himno a Dionisio o a las fuerzas primordiales de la naturaleza, una visión sobrecogedora del cosmos desde la hipersensibilidad del compositor. Pocos directores logran semejante interpretación.

\section{Quinta Sinfonía}

La quinta sinfonía, composición que prescinde de la voz humana, es tal vez la obra más conocida de Mahler por su movimiento lento, el famosísimo Adagietto, que llegó al gran público al ser utilizado por Visconti como tema principal de la película Muerte en Venecia basada en el relato de Thomas Mann del mismo nombre. ${ }^{2}$ Mahler trabajó en la composición durante el verano de 1901 y el otoño de 1902, precisamente en los años en que conoció a Alma Schindler y contrajo matrimonio con ella. Por ello se ha dicho que en esta sinfonía están contenidos los sentimientos amorosos del artista, que el Adagietto es en realidad una carta de amor a su joven y bella esposa, lo cual es incorrecto. En realidad, la sinfonía expresa el paso de la desgracia al triunfo total y sublime. Como en su segunda y tercera sinfonías, Mahler comienza con una impresionante marcha fúnebre, sólo sobrepujada, quizá, por el inicio de "La Resurrección". El anunciamiento de la trompeta da paso a un episodio de intenso dolor y desesperación, incompatible con el idilio amoroso que vivía con Alma. Le sigue un tiempo extremadamente agitado, igualmente convulso y presa de

${ }^{2}$ Mann tenía una fascinación especial por la música. Probablemente el personaje principal de Muerte en Venecia sea Mahler, como lo es Schoenberg en su Doktor Faustus. 
la ansiedad. El Scherzo, tercer movimiento, verdadero clímax de la sinfonía, denota endemoniado la cúspide del héroe que está en goce total de sus poderes. Este movimiento es un verdadero tour de force de dimensiones hasta ese entonces ignotas. El célebre Adagietto es una pieza de marcado lirismo, infinitamente bella, relativamente corta -unos diez minutos-, en donde únicamente se hace uso del harpa y de las cuerdas. A pesar de ser muy asimilable para cualquier oído, no por ello deja de ser profundo, e incluso triste. En este movimiento encontramos una profunda y divina resignación. Reducirlo a mera ensoñación me parece inadecuado, como también lo sería exagerar su contenido. No obstante, en esta música nos enfrentamos a una visión muy peculiar del artista que no queda del todo clara y de la cual vagamente se puede decir que, en todo caso, es un pasaje de serena reflexión y meditación que antecede al júbilo por la vida que es el último movimiento, una pieza orquestal brillantísima, llena de contrapunto y de optimismo. Dicho movimiento siempre ha desconcertado a quienes han visto en Mahler una persona pesimista y autodestructiva. En realidad, el final de la quinta es una adhesión total e imponente a la alegría de la vida. Mahler no ignoraba sus potencialidades y sabía perfectamente que estaba haciendo música para oídos nuevos como los de sus amigos Schoenberg y Berg, quienes en esta composición vieron el comienzo exacto de la nueva música. Mahler, en una carta a su esposa desde Colonia, lugar en el que dirigía los ensayos para estrenar su nueva composición, dijo: “¡Ay, si pudiera estrenar mi sinfonía cincuenta años después de mi muerte!" Sus palabras estaban llenas de verdad y no sólo deben aplicarse a la quinta sinfonía, sino a toda su obra. La música de Mahler, por sus dificultades extremas, por su complejidad, por el marcado antisemitismo de la época, por la apatía de muchos directores, por el poco entendimiento de los críticos -es lamentable ver cómo los libros sobre música que se publicaron en el período que va de la muerte de Mahler (1911) hasta los años sesenta presentan artículos diminutos menospreciando o demeritando al genial compositor-, y muchas otras razones, cayó casi en el olvido. Si bien no faltaron los mahlerianos, como Bruno Walter, en términos 
generales no se alcanzó a apreciar en sus reales dimensiones la obra del converso. Afortunadamente, hubo un 'renacimiento mahleriano' cuando los entonces jóvenes directores de los años sesenta, Bernard Haitink y Leonard Bernstein - probablemente, y en términos generales, los mejores intérpretes de Mahler- mostraron un interés inusitado por esta música. De ahí se expandió el boom y por decenas surgieron grabaciones de las sinfonías que además se programaron prolijamente en las principales salas de concierto de Europa y Estados Unidos. Hoy en día, ninguno de los grandes directores -salvo los que se dedican a estilos muy específicos anteriores a los románticos y hacen grabaciones con instrumentos originales de las diversas épocas- se atreve a poner a Mahler en el librero. ${ }^{3}$

\section{Sexta Sinfonía: Trágica}

La sexta sinfonía es otra de sus más grandes creaciones. Berg la llamaba "la única Sexta, a pesar de la Pastoral". Otto Klemperer dijo que el último movimiento era un 'cosmos en sí mismo'. Esta sinfonía también fue puesta en el librero, antes que en el atril, pues se la consideraba extremadamente compleja: había que contratar más músicos y ensayar más tiempo. Las demandas de Mahler sólo podían ser satisfechas por pocos directores y pocas orquestas. En esta sinfonía, y no en la quinta, encontramos una clara alusión a Alma (segundo tema del primer movimiento). La compuso durante los años 1903 y 1904, tiempo en el que la relación con Alma marchaba satisfactoriamente, momentos de felicidad que se intensificaron con las dos niñas del matrimonio. En suma, un tanto desconcertante, pues tal dicha no se ve reflejada en la música, ya que el tono de la composición es trágico. No cabe duda que la música de Mahler es una de las más subjetivas y autobiográficas que existen, y por esta razón los tres implacables y violentos golpes de

${ }^{3}$ En nuestro país tenemos un gran intérprete de Mahler. Me refiero al maestro Enrique Arturo Dimecke. 
martillo en el final de la obra son enigmáticos y proféticos. Expresan, como ha dicho el crítico Michael Kennedy, 'la caída del héroe'. En efecto, poco después Mahler cayó al más profundo abismo y recibió en carne propia cada uno de los implacables golpes: en 1907 murió su hija mayor, a quien adoraba; ese mismo año, por intrigas y presiones se vio forzado a renunciar de su puesto como director de la Ópera de Viena; y, por si fuera poco, también en ese año, se le diagnóstico una mortal enfermedad del corazón. Tal vez esto último haya dado lugar a que Mahler, de forma supersticiosa, eliminara de la partitura el tercer golpe de martillo, aunque son varios los directores que lo incluyen en sus interpretaciones. Y si acaso todo esto no fuera suficiente, después de tan terribles acontecimientos, Alma y Mahler llegaron al punto más ominoso de su relación: ella cometió adulterio. De alguna manera, el hipersensible compositor vaticinó su propio ocaso. En una carta a su amigo Berliner, fechada en otoño de 1904, escribe: "Mi sexta sinfonía está acabada; yo también." Podríamos agregar que no solamente su sinfonía y él estaban acabados, sino también Europa, pues adhiriéndome a la opinión del respetado musicólogo Hans Ferdinand Redlich, es válido, aunque osado, decir que con esta sinfonía Mahler "profetizó los horrores de este mundo asolado por dos guerras". En efecto, esta sinfonía puede ser descrita, en palabras de Eggebrecht, como "el desmoronamiento de la felicidad y el peso del dolor". Si las observaciones de Redlich y Eggebrecht son correctas, entonces Mahler se convertiría en un verdadero profeta.

\section{Octava Sinfonía: de los mil}

La octava sinfonía, compuesta en 1906, es conocida como sinfonía de los mil por la enorme cantidad de músicos, solistas y coros requeridos, que en realidad no son mil, sino tal vez doscientos, aunque para su estreno en Munich en 1910, bajo la dirección del autor, se emplearon mil treinta personas. De cualquier forma, salvo Berlioz, ningún compositor había requerido tales fuerzas. Esta obra, que dedicó a su mujer, consta 
de dos partes: el himno medieval Vieni Creator Spiritus que data de la primera mitad del siglo IX, y el final de la segunda parte del Fausto de Goethe. Es una composición colosal en donde vuelve a incluir la voz humana, y en la que trabajó infatigablemente durante unos tres meses durante el verano de 1906. La consideraba una de sus máximas creaciones. En una carta fechada en agosto de ese año, Mahler escribe: "He concluido mi Octava; es lo más grande que he hecho hasta ahora. $\mathrm{Y}$ tan peculiar en contenido y forma, que ni siquiera puede escribirse sobre eso. Imagínese que el Universo empieza a sonar y hacer música. No son ya voces humanas, sino planetas y voces que giran." Créanme cuando les digo que música como esta nunca antes ni después se ha compuesto. Con ella Mahler abraza eternamente el universo y se postra ante la Divinidad, o, por qué no decirlo, se une a la Divinidad. Quien califique a esta obra como producto de un espíritu perturbado y extravagante sólo demostrará su pequeñez y su nula comprensión. Esta música no tiene igual en el mundo entero. Es gigantesca, inmensa, como lo es el cosmos. Es una representación total y absoluta del universo. Es el triunfo del hombre. Está hecha para gloria del género humano. Ante ella, el auditor siente intensamente la fuerza del Creador y no puede

132 más que terminar exhausto, apabullado, como si un huracán le hubiese cogido y sacudido, como si una incandescente luz le hubiese cegado. Esta tremenda obra nos muestra lo pequeño y grandioso que puede ser el hombre: diminuto ante Dios y enorme ante los hombres pequeños. Sin duda, la octava sinfonía debe considerarse como una de las obras artísticas más importantes de la humanidad. La dedicación a Alma se queda corta -si no es que francamente ridícula-. Más bien, esta sinfonía fue compuesta para el alma universal, producto del amor en su más alta expresión, en su grado supremo y omniabarcante, aquel amor que nada tiene que ver con el amor mundano. No es el amor del hombre lo que está en la octava sinfonía. No. Es el amor de Dios anunciado por medio de Mahler. 


\section{Novena Sinfonía}

Si tuviera que escoger de todas la obras de Mahler sólo una, sin meditarlo mucho me quedaría con la novena sinfonía. Me parece que es su verdadera obra maestra. Fue compuesta entre 1908 y 1909, momentos en que su crisis marital llegó al máximo: la joven Alma trataba de recuperarse del duro golpe que fue la muerte de su hija María Anna y el atormentado Gustav se hundía cada vez más en la depresión -pocos meses después, en 1910, mientras Mahler ensayaba su octava sinfonía en Munich, Alma conoció y cometió adulterio con Walter Gropius, que se enamoró perdidamente de ella, y con el que, tres años después de la muerte de Gustav, contraería matrimonio-. La novena se estrenó en 1912, en Viena, junto con el Pierrot Lunaire de Schoenberg, ambas obras dirigidas magistralmente por el joven Bruno Walter. Fue la última composición que pudo finalizar. Murió cuando apenas trabajaba en bosquejos de la décima.

Alban Berg, ferviente admirador de Mahler -lo consideraba casi una líder espiritual-, vislumbró el ocaso que se avecinaba y en una carta escribió, a propósito de la novena, lo siguiente: "Es la expresión de un amor inaudito a este mundo, al anhelo de vivir en paz en él, de apurar el gozo de la naturaleza hasta sus más profundas profundidades... antes de que llegue la muerte."

El director holandés Mengelberg, haciendo anotaciones a la partitura de la novena, describe con gran acierto lo que pasaba Mahler y la define como una 'despedida de la vida' o un 'canto del cisne'. En realidad sí es el adiós último de Mahler al mundo, como se aprecia particularmente en el último movimiento, un sublime y dolorido adagio, infinitamente bello e introspectivo que revela la verdadera alma del compositor y nos aproxima íntimamente a su espíritu. De algún modo, quien lo escucha comprende que Mahler, más que esperar la muerte, esperaba la vida eterna. Si no hubiese escrito otra cosa más que este adagio, de cualquier forma se situaría entre los más grandes compositores de la historia. Mengelberg apunta: "La novena sinfonía 
es despedida de todo lo que él amaba, y del mundo [...] Primer movimiento: despedida de sus seres queridos, su mujer, su hija, ¡nostalgia! (la más profunda) [...] Segundo movimiento: 'Danza Fúnebre' (Has de bajar a la tumba). Mientras vives te consumes, humor airado. [...] Tercer movimiento, humor negro, ¡trabajo, creación, todo esfuerzo vano por escapar de la muerte...! [...] Cuarto movimiento, canción de la vida de Mahler [...] Él siente y canta su adiós..." La música occidental debió terminar con la última nota de esta sinfonía.

\section{Alma Mahler}

Alma María Schindler (1879-1964) era hija del pintor de la corte de Viena, Jakob Emil Schindler. Cuando su padre murió, su madre se casó con el discípulo de su marido, Karl Moll, también importante pintor y uno de los fundadores del movimiento de la Secesión, al que pertenecieron artistas de la talla de Otto Wagner, Gustav Klimt, Oskar Kokoschka y Alfred Roller, entre otros, y con los que Alma tuvo estrecho contacto, ya que la casa de su padrastro era uno de los más importantes centros de reunión del movimiento. Después de la boda de Alma y Gustav en 1902, el músico también se relacionó con los secesionistas, especialmente con Roller, que se convirtió en el escenógrafo de las producciones de la Ópera de Viena. Aunque Mahler entró al círculo de la Secesión, nunca perteneció a él.

Alma era una persona sumamente educada: sabía de literatura, de artes plásticas y de música, virtudes que sumadas a su gran belleza la hacían una de las mujeres más deseadas y cortejadas de Viena. De hecho incursionó en la composición musical y, guiada por su amigo y maestro Alexander von Zemlinsky, dio muestras de talento admirable. Desgraciadamente, poco después de la boda, Mahler hizo lo posible para que su esposa - a la que le llevaba casi veinte años- abandonara paulatinamente la composición y la redujo a simple copista de sus obras, cuestión de la cual Alma en sus memorias se queja con cierta amargura. 
Tal vez Alma no fue la compañera adecuada de un hombre genial, difícil e hipersensible. En cierta medida, ella nunca dejó de ser superficial y frívola, aunque existen testimonios (de ella misma, algunos) en el sentido de que sí estaba consciente de la clase de genio que era Gustav. Era una mujer de sociedad, sabedora de su belleza y de los deseos que despertaba en los hombres. Mahler vivía en un mundo aparte, encerrado en su arte, refugiado en sí mismo, aislado mientras componía; era retraído y no figuraba entre sus intereses convertirse en un socialite. Esto pudo haber sido un factor que contribuyó a que la inquieta joven se relacionara amorosamente, durante su matrimonio y después de la muerte de Gustav, con importantes figuras intelectuales y artísticas de Viena, entre las que destacan Oskar Kokoschka, Walter Gropuis y Franz Werfel -con éstos dos últimos contrajo nupcias sucesivamente después de la muerte de su marido-.

Alma, decía, cometió adulterio con Walter Gropius -el célebre arquitecto fundador de la Bauhaus de Weimar- en 1910. Al enterarse, Mahler quedó devastado. Tal vez éste debió ser el cuarto golpe de martillo que nunca existió en su sexta sinfonía. Ante crisis tan grande, Gustav decidió consultar al famoso psicoanalista Sigmund Freud. Alma permaneció pasiva, en un papel que podríamos calificar de 'víctima', lo que no es mera apreciación subjetiva de quien escribe, pues si observamos las memorias de esta interesante mujer, escritas en 1939, encontraremos que se justifica diciendo que el 'incidente' con Gropius -así llama al affaire-se debió a la condición psicológica de una mujer incomprendida y descuidada por su marido. Tal vez era ella la que necesitaba ver a Freud.

\section{El doctor Freud}

Completamente abatido y devastado por los golpes sufridos en los últimos tres años, especialmente la muerte de su hija y la infidelidad de su esposa -recordemos que poco después de la muerte de su pequeña tuvo un ataque cardíaco al que pudo sobrevivir pero jamás 
sobreponerse-, Mahler visitó al doctor Freud en el verano de 1910, poco después de cumplir cincuenta años. La entrevista que sostuvieron estos dos grandes hombres tuvo lugar en Holanda, y al parecer fue la única, así que la brevedad del encuentro en un hotel de Leiden debe mantenernos atentos para evitar exagerar las interpretaciones de Freud, las cuales, a su vez, han sido interpretadas tanto por sus seguidores como por sus desertores. Es famoso entre los freudianos el 'caso Mahler'. Alphons Silbermann escribe: "De este encuentro entre ambas lumbreras, apresuradamente organizado, han quedado ciertas afirmaciones que se citan para iluminar el alma de Mahler y su música. Así, según una de ellas el analista debió decirle a Mahler: 'Conozco a su mujer. Amaba a su padre, y sólo puede buscar y amar a ese tipo. Su edad, que usted tanto teme, es precisamente lo que le hace atractivo para su mujer. ¡No se preocupe! Usted quiere a su madre, ha buscado en toda mujer su tipo. Su madre estaba amargada y sufría, y esto es lo que usted quiere inconscientemente de su mujer' [...] En otra carta de Freud escrita más o menos un cuarto de siglo después del encuentro con Mahler, se lee: 'Analicé a Mahler [...] durante una tarde en Leiden y si puedo creer los testimonios, logré mucho con él. Descubrimos

136 en recorridos sumamente interesantes por su vida sus condiciones amorosas, en especial su Complejo de María (vinculación a la madre); tuve ocasión de admirar la genial capacidad de entendimiento de aquel hombre. No se hizo ninguna luz sobre la fachada sintomática de su neurosis obsesiva'."

Así que, al parecer, Freud no logró mucho con Mahler, pues su relación amorosa con Alma no cambió. Silbermann observa que "presentar a Sigmund Freud como omnisapiente, a Alma Mahler como la esposa sufriente y a Mahler como neurótico no ayuda en modo alguno al acercamiento a su música". En efecto, aunque Mahler adoraba a su esposa, la fascinación por la muerte y el deceso de su hija le tenían más abatido; no esa visión enfermiza de la muerte, sino la idea de una vida eterna, como se muestra en su segunda sinfonía y en la sobrecogedora novena. 


\section{Epílogo}

Este apasionante hombre es uno de los genios más controvertidos por su carácter hipersensible. Con él, cualquier psicoanalista podría penetrar las profundidades más íntimas del ser humano. En su música aparecen con claridad su amor por la naturaleza, sus impulsos espirituales, sus tormentos mentales. Con Mahler puede decirse que se cierra ese sueño decimonónico conocido como romanticismo y se abre la música del siglo XX. No sin razón, Bernstein ha dicho que Mahler es el punto de inflexión musical decisivo de nuestro siglo. En Mahler encontramos la síntesis de la canción popular; de Beethoven, de Bruckner, de Wagner, entre otros, y una visión imponente de la fuerza del Creador. Hay también una cierta sensación de panteísmo.

Las intrigas, el antisemitismo y otros bajos instintos que produjeron su dimisión en 1907 como director de la Ópera de Viena sólo demuestran lo absurdo, estúpido, pequeño y ruin que puede ser el hombre insensible. Algo así como lo que expresa Milos Forman en su Amadeus: el horrendo y oprobioso triunfo de la mediocridad sobre la genialidad. Los ataques de periódicos antisemitas como el Reichpost, el Deutsche Zeitung y del mismo alcalde de Viena, Karl Lueger, líder del partido cristiano-social, y de los directivos de la Ópera estatal son escalofriantes: decadente, antialemán, judaizante, antiartístico, criminal, el colmo de la desvergüenza, el mono judío, y otras tantas injurias que no voy a reproducir, llevaron a nuestro compositor a una presión extrema e insoportable que no podía ni quiso tolerar. No tuvo otra opción que renunciar. Así creyeron triunfar sus enemigos, pero, ¿quién se acuerda de ellos? Nadie. Están muertos y se perdieron para siempre en los abismos del olvido.

Al salir de Viena, su nombre y prestigio como director y compositor eran conocidos en Europa y en América, por lo que de inmediato fue invitado para dirigir la Ópera Metropolitana de Nueva York. En la cúspide de sus fuerzas y de su fama, pocos meses después del estreno de su octava sinfonía, de vuelta en América, cayó enfermo. Regresó a 
Europa, recibió tratamiento infructuoso en París y, en camino a Viena, murió el 18 de mayo 1911.

Con su obra, Mahler trascendió todas las fronteras: ya no era judío, ni alemán, ni austríaco, ni católico. Mahler fue entonces la apoteosis del hombre, el espíritu universal. Así, ya no hay calificativos para el Maestro: lo único que podemos decir-como Dios dijo a Moisés cuando éste le preguntó su nombre: 'Yo soy el que soy'- es que Mahler es Mahler.

\section{Las mejores grabaciones de Mahler}

- Sinfonía no. 2, “Resurrección”. Sin duda la mejor versión es la última grabación, cien por ciento digital, del grandioso Bernard Haitink, en Philips. La versión digital de Leonard Bernstein en Deutsche Grammophon con la orquesta de Nueva York es apoteósica. Hay que evitar a Slatkin en Telarc, a Inbal en Denon, a Wit en Naxos y a Rattle en EMI.

- Sinfonía no. 3. Insisto en Haitink, ya sea su versión de la década de los sesenta con la Royal Concertgebow o la grabación digital de su nuevo ciclo Mahler, ambas en Philips.

- Sinfonía no. 5. Bernstein puede resultar un tanto extravagante, pero no cabe duda que su versión digital con la Filarmónica de Viena en Deutsche Grammophon conmoverá a muchos. Recomendable sigue siendo Haitink en Philips. Otra distinguida versión es la de Wyn Morris con la Sinfónica de Londres en IMP Classics. Una versión muy barata de la quinta con una excelente interpretación es la de Avi Ostrowsky en el sello Discover. Posiblemente las versiones digitales de Abbado y de Boulez, ambas en Deutsche Grammophon, no llenen las expectativas del melómano.

- Sinfonía no. 6. Tal vez la mejor versión sea la de Bernstein con la Filarmónica de Viena en Deutsche Grammophon. Como segunda opción está la versión de 1977 de Karajan con la 
Filarmónica de Berlín, también en Deutsche Grammophon. Hay que evitar a Chailly en Decca, a Wit en Naxos, a Metha en Teldec y a Järvi en Chandos.

- Sinfonía no. 8. Haitink en Philips, Solti en Decca o Morris en IMP Classics. Muy buenas versiones también la de Segerstam en Chandos, la de Sinopoli en Deutsche Grammophon y la de Tennstedt en EMI. Sugiero evitar a Shaw en Telarc y a Colin Davis en RCA.

- Sinfonía no. 9. Las opciones más claras siguen siendo Bernstein y Haitink. En este caso en particular, y después de mucho deliberar, yo me quedo con Bernstein y el Concertgebow.

- Sinfonías completas. Existen varias ediciones: Bernstein, Kubelik, Abbado y Sinopoli en Deutsche Grammophon, Maazel en Sony, Solti en Decca, Haitink (análoga) en Philips, Tennstedt en EMI. Por la relación precio y nivel artístico, recomiendo a Haitink y a Tennstedt. Si el lector puede darse el lujo, no dude en adquirir el ciclo de Bernstein. 
CITAM Derechos Reservados.

La reproducción total o parcial de este artículo se podrá hacer si el ITAM otorga la autorización previamente por escrito. 